\title{
Role of dopant cations in the gelation behaviour of silica sols
}

\author{
A PATRA and D GANGULI \\ Sol-Gel Laboratory, Central Glass \& Ceramic Research Institute, Calcutta 700 032, India
}

\begin{abstract}
Gelation times of tetraethyl orthosilicate-derived sols containing selected di- to tetravalent cations as dopants were noted at different temperatures $\left(15^{\circ}-50^{\circ} \mathrm{C}\right)$. An analysis of these data, in conjunction with relevant published information, led to the tentative conclusions that (i) unhydrolyzed cations in bare form linked negatively charged silicate polymers in sols, thereby accelerating gelation and (ii) hydrolyzed cations retarded the process by offering molecular size-related hindrance and competition for the available water for hydrolysis.
\end{abstract}

Keywords. Silica sol; sol-gel transition; dopant cations.

\section{Introduction}

The phenomenon of gelation of silica sols in presence of dopant cations has been attracting the attention of researchers from the early part of this century (Dienert and Wandenbulcke 1924; Hurd et al 1958) till date (Bansal 1990; Patra and Ganguli $1992 \mathrm{a}, \mathrm{b})$. The common approach followed in most of these investigations was to find out if and how the process of aggregation of silicate species in a sol (reflected by, among others, the gelation time) was accelerated or retarded by a dopant cation. The issue has gained importance in recent times because of the current interest in doped silica gel-glass optics (e.g. Moreshead et al 1990; Thomas et al 1992), special glasses (Aizawa et al 1994) and silicate catalysts (e.g. Lopez et al 1991) including zeolite precursors (McCormick et al 1987, 1989) of tailor-made specifications, and the expected influence of the dopants on the gel structures (Ganguli 1988; Murakata et al 1992). Gelation time is also an indicator of the workability of a sol and therefore, is of great practical significance in sol-gel processing.

Effects of various cations on the gelation behaviour of alkali silicate or alkoxidederived sols have been studied (discussed in detail later). However, no general picture of the effect seems to have emerged. In addition, parallel investigations have sometimes led to conflicting conclusions, demanding further study. The present work attempts to re-examine the above phenomenon in the light of existing data and new information on gelation (used as a broad term to include condensation and aggregation of polymeric units) of alkoxide- derived silica sols in presence of selected di- to tetravalent cations.

\section{Experimental}

All the sols were prepared at $25^{\circ}-27^{\circ} \mathrm{C}$ from alcohol-free (initially) alkoxide-water-acid systems. Tetraethyl orthosilicate (TEOS) of purum grade was used as the source of silica with $\mathrm{H}_{2} \mathrm{O}$ : TEOS : $\mathrm{H}^{+}$molar ratio at $14: 1: 0.01$. Chations in required proportions were added via inorganic compounds $(\mathrm{Pb}-, \mathrm{Zn}$ - and $\mathrm{La}$-nitrates, ammonium 
ceric nitrate, Al-chloride, $\mathrm{Z}_{\boldsymbol{r}}$-oxychloride and boric acid) dissolved in deionized water. $\mathrm{HNO}_{3}$ (for nitrates) or $\mathrm{HCl}$ (for other compounds) was used as catalyst. The temperature of the hazy two-phase system thus obtained increased to $70^{\circ}-80^{\circ} \mathrm{C}$ with formation of a clear sol, but came back to ambient conditions within about $15 \mathrm{~min}$. The pH was adjusted to 3.5 by addition of dilute $\mathrm{NH}_{4} \mathrm{OH}$ solution. All the chemicals were of $\mathrm{AR}$ or equivalent grade.

Sol-gel transition was studied at different temperatures $\left(15^{\circ}-50^{\circ} \mathrm{C}\right)$ in a constant temperature bath $\left( \pm 1^{\circ} \mathrm{C}\right)$. Sols of $15 \mathrm{ml}$ volume in closed containers were used. Gelation times at $25^{\circ} \mathrm{C}$ and higher temperatures were repeated for check under similar conditions; the differences were found to be reasonably small for the present purpose. However, mean values (2-3 experiments) were used in this work.

\section{Results}

Tables $1-5$ present information on the gelling time of silica sols doped with $\mathrm{B}^{3+}$, $\mathrm{Al}^{3+}, \mathrm{La}^{3+}, \mathrm{Zr}^{4+}$ and $\mathrm{Ce}^{4+}$ at different temperatures. Similar data for $\mathrm{Pb}^{2+}$ and $\mathrm{Zn}^{2+}$ have been reported earlier (Patra and Ganguli 1992a,b) and will not be presented here in full. The data for $40^{\circ} \mathrm{C}$ (not given in tables 1-5) for all the seven cations have been pictorially presented in figure 1 for a ready comparison of relative trends of gelation. Note that all the sols were cast at a final $\mathrm{pH}$ of 3.5 , requiring similar additions of $\mathrm{NH}_{4} \mathrm{OH}$; the effect of $\mathrm{NH}_{4}^{+}$has therefore been considered to be similar in all cases.

\section{Discussion}

\subsection{Earlier observations on gelation of doped silica sols}

The earliest experiments (e.g. Hurd et al 1958) on gelation, coagulation or aggregation

Table 1. Gelling times of boron-doped silica sols.

\begin{tabular}{ccccc}
\hline \multirow{2}{*}{$\begin{array}{c}\text { Equivalent } \\
\text { mol\% } \mathrm{B}_{2} \mathrm{O}_{3}\end{array}$} & $15^{\circ} \mathrm{C}$ & $25^{\circ} \mathrm{C}$ & $30^{\circ} \mathrm{C}$ & $50^{\circ} \mathrm{C}$ \\
\cline { 2 - 5 } & 27.38 & 8.91 & 4.95 & 0.55 \\
1.5 & 33.08 & 9.38 & 5.16 & 0.58 \\
2.5 & 40.00 & 10.83 & 7.08 & 1.00 \\
5.0 & 45.00 & 15.58 & 8.33 & 1.13 \\
\hline
\end{tabular}

Table 2. Gelling times of aluminium-doped silica sols.

\begin{tabular}{cccc}
\hline \multirow{2}{*}{$\begin{array}{c}\text { Equivalent } \\
\text { mol\% } \mathrm{Al}_{2} \mathrm{O}_{3}\end{array}$} & $15^{\circ} \mathrm{C}$ & $30^{\circ} \mathrm{C}$ & $50^{\circ} \mathrm{C}$ \\
\cline { 2 - 4 } & 22.00 & 5.33 & 0.75 \\
0.2 & 39.81 & 7.00 & 1.08 \\
1.0 & 92.00 & 13.75 & 2.17 \\
\hline
\end{tabular}


Role of dopant cations in silica sols

Table 3. Gelling times of lanthanum-doped silica sols.

\begin{tabular}{cccc}
\hline \multirow{2}{*}{$\begin{array}{c}\text { Equivalent } \\
\text { mol\% } \mathrm{La2O}_{3}\end{array}$} & $15^{\circ} \mathrm{C}$ & $25^{\circ} \mathrm{C}$ & $50^{\circ} \mathrm{C}$ \\
\cline { 2 - 4 } 0.5 & 18.62 & 4.57 & 0.45 \\
1.0 & 12.30 & 3.16 & 0.35 \\
3.0 & 6.30 & 1.99 & 0.29 \\
5.0 & 3.01 & 0.80 & 0.17 \\
\hline
\end{tabular}

Table 4. Gelling times of zirconium-doped silica sols.

\begin{tabular}{cccc}
\hline \multirow{2}{*}{$\begin{array}{c}\text { Equivalent } \\
\text { mol\% ZrO2 }\end{array}$} & $15^{\circ} \mathrm{C}$ & $25^{\circ} \mathrm{C}$ & $50^{\circ} \mathrm{C}$ \\
\cline { 2 - 4 } & 26.92 & 10.59 & 1.99 \\
1.5 & 47.86 & 17.58 & 1.83 \\
3.0 & 63.00 & 21.88 & 1.92 \\
5.0 & 5.50 & 3.02 & 0.78 \\
\hline
\end{tabular}

Table 5. Gelling times of tetravalent cerium-doped silica sols.

\begin{tabular}{cccc}
\hline $\begin{array}{c}\text { Equivalent } \\
\text { mol\% } \mathrm{CeO}_{2}\end{array}$ & $15^{\circ} \mathrm{C}$ & $30^{\circ} \mathrm{C}$ & $50^{\circ} \mathrm{C}$ \\
\cline { 2 - 4 } & 23.00 & 5.89 & 1.12 \\
3.0 & 19.49 & 5.25 & 0.92 \\
5.0 & 15.14 & 4.07 & 0.80 \\
\hline
\end{tabular}

(taken to be synonymous here) in silica sols as a function of the type of electrolyte present in the system showed monovalent cations to accelerate the process in the order $\mathrm{K}^{+}>\mathrm{NH}_{4+}>\mathrm{Na}^{+}>\mathrm{Li}^{+}$at $\mathrm{pH}=4 \cdot 8$. Recent work of Bansal (1990) confirmed the accelerating action of $\mathrm{Li}^{+}$and $\mathrm{Na}^{+} ;$a similar behaviour was also noted for all the alkali cations and tetramethyl ammonium, $\left(\mathrm{CH}_{3}\right)_{4} \mathrm{~N}^{+}$(Wijnen et al 1993) by measuring fractal aggregate size as a function of time at $\mathrm{pH}=4 \cdot 0$.

Among the divalent ions, $\mathrm{Mg}^{2+}, \mathrm{Ca}^{2+}, \mathrm{Sr}^{2+}, \mathrm{Pb}^{2+}$ and $\mathrm{Zn}^{2+}$ have been shown to accelerate gelation (Bansal 1990; Patra and Ganguli 1992a,b) at $\mathrm{pH}$ values ranging between 3.5 and 4.3. Wijnen et al (1993), on the other hand, found the initial silicate aggregate growth to be very slow in presence of $\mathrm{Mg}^{2+}$ at $\mathrm{pH}=4.0$ and considered it to be a retarding process. Divalent copper was shown by Bansal (1990) to retard gelation.

$\mathrm{Al}^{3+}, \mathrm{Y}^{3+}$ and $\mathrm{La}^{3+}$ have been reported to hinder gelation (Bansal 1990); boron is known to behave similarly (Woignier et al 1984), though no detailed information is on print. Large amounts $(10-50 \mathrm{wt} \%)$ of $\mathrm{ZrO}_{2}$ in $\mathrm{SiO}_{2}$ sols have been shown to increase the gelling time drastically (Klein 1987). 


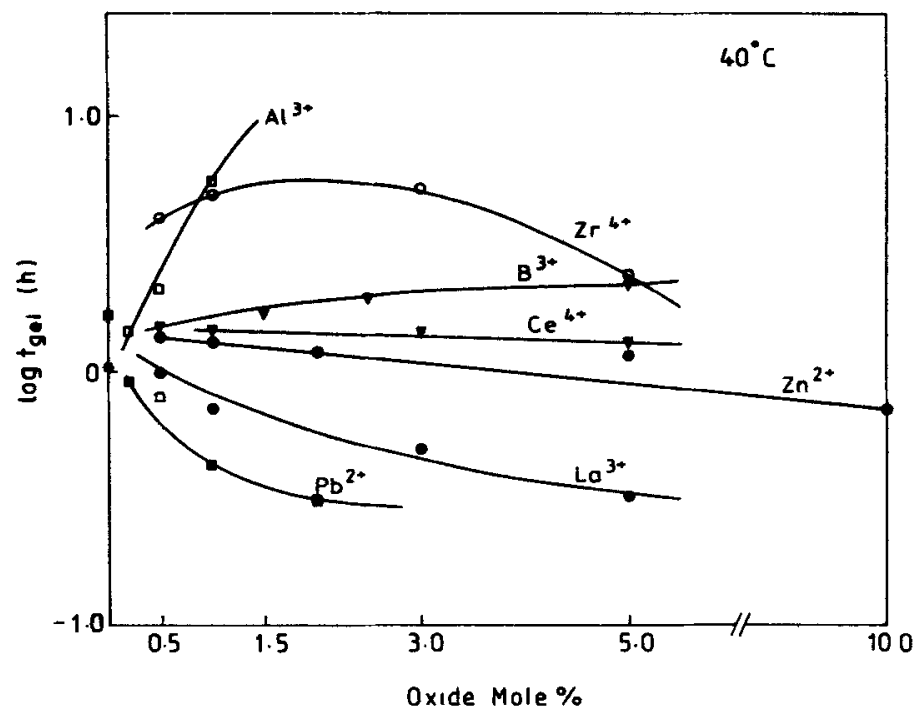

Figure 1. Gelation times at $40^{\circ} \mathrm{C}$ of some bi- to tetravalent cation doped silica sols (derived from TEOS) prepared at a final sol $\mathrm{pH}$ of 3.5 . The curves are only visual aids, and do not have any other significance. The asterisk on the $\mathrm{Y}$-axis indicates the gelling time of a pure silica sol catalyzed with $\mathrm{HCl}$; the filled box on the $\mathrm{Y}$-axis indicates the same, catalyzed with HNO3.

\subsection{The past and present results and their interpretation}

A comparison of the results presented in tables $1-5$ and figure 1 with the published information assembled in $\$ 4.1$ gives a first hand indication of a general trend of the role of cations in the gelation of a silica sol: (i) Monovalent ions in general accelerate gelation; (ii) divalent ions mostly accelerate gelation (except $\mathrm{Cu}^{2+}$ ); and (iii) small trivalent and tetravalent ions hinder gelation, and ions with radius $\sim 1 \AA$ may do so under suitable conditions.

Under the conditions of this work (i.e. alcohol-free solution) the first major interaction of the cations would be with water molecules, i.e. hydration or hydrolysis. Even when alcohol was present in the original solution, monovalent cations have been shown to be solvated by water rather than ethanol (Sanchez and McCormick 1991). This indicates a clear relationship between hydrated dopant cations and quick gelation. Considering the fact that cations with small size and high formal charge hydrolyze easily in aqueous solutions of suitable pH (Baes and Messmer 1976; Ramsay 1994), it was thought proper to examine the present data in this light.

Figure 2, re-assembled from Baes and Messmer (1976), indicates that at $\mathrm{pH}=3.5$, cations which clearly accelerated gelation in this work, i.e. $\mathrm{Pb}^{2+}, \mathrm{Zn}^{2+}, \mathrm{La}^{3+}$ also remained predominantly hydrated; $\mathrm{B}^{3+}$ and $\mathrm{Zr}^{4+}$ which hindered gelation (except for $5 \mathrm{~mol} \% \mathrm{ZrO}_{2}$ ) were hydrolyzed. Boron always remains hydrolyzed in aqueous solution and the reaction steps indicated by Irwin et al (1987) clearly show how it hinders hydrolysis-condensation of Si-alkoxy group. Zirconium forms a cyclic tetramer, $\left[\mathrm{Zr}_{4}(\mathrm{OH})_{8}\left(\mathrm{H}_{2} \mathrm{O}\right)_{8}\right]^{8+}$ in oxychloride solutions (Clearfield and Vaughan 1956). $\mathrm{Al}^{3+}$ also hindered gelation, though figure 2 is not clear about its hydrolyzability at pH $=3 \cdot 5$. Recently, Kloprogge et al (1993) used NMR data to show that $\mathrm{AlOH}^{2+}$ started 


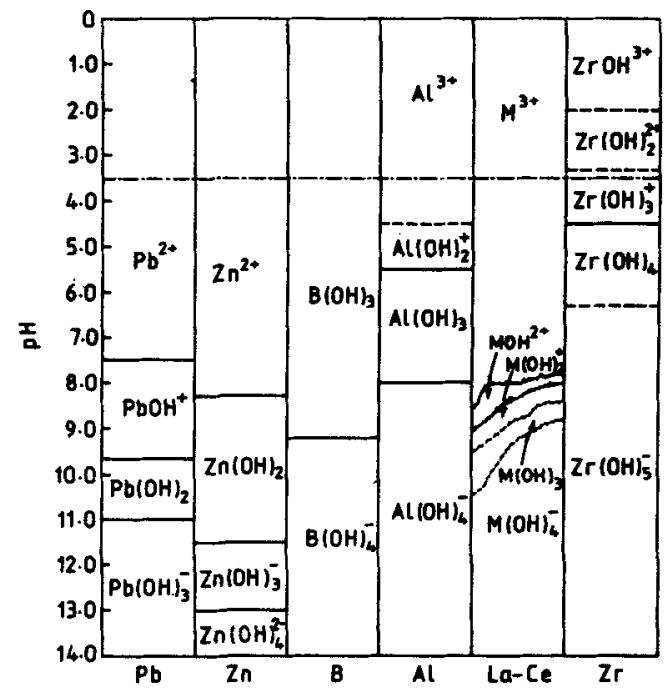

Figurc 2. P'redominance diagrams for hydration/hydrolysis of cations related to the present work in aqueous solutions of different pH values. Reassembled from Baes and Messmer (1976).

forming at $\mathrm{pH}$ 3-3.7 in $\mathrm{AlCl}_{3}$ or $\mathrm{Al}\left(\mathrm{NO}_{3}\right)_{3}$ solutions. Bottero et al (1982) identified $\mathrm{Al}_{2}(\mathrm{OH})_{2}^{4+}$ species at $\mathrm{pH} 3$ at the expense of at least $10 \%$ of monomers. $\mathrm{A}$ rise in temperature during sol preparation (see \$2) can be of assistance in the formation of larger polynuclear species. This is also valid for boron and zirconium.

Tetravalent cerium is expected to take part in complexation in most low-pH aqueous solutions. However, it is also a strong oxidizing agent and can be reduced, at least in part, by water (Moeller 1973; Greenwood and Earnshaw 1984) or species present in aqueous solutions to form hydrated (at $\mathrm{pH}=3.5$ ) $\mathrm{Ce}^{3+}$, promoting gelation in silica sols.

Sanchez and McCormick (1991) suggested formation of ion-pair complexes between alkali cations and negatively charged silicate groups in TEOS sols to explain enhanced condensation. Patra and Ganguli (1992a) suggested formation of transition state bonds between $\mathrm{O}^{-}$(of silicate polymers) and $\mathrm{M}^{\mathrm{z+}}$ cations to accelerate gelation. In both cases, facile shedding of hydration shells (thinner for larger ions) has been assumed. This generalized approach has been found to fit satisfactorily in most cases of relatively quick gelation of cation-doped silica sols.

A simple correlation between a hydrolyzed dopant cation and retardation of gelation of a silica sol seems difficult because of the wide differences among the nature and products of hydrolysis (and eventually, polymerization) of different cations under a given set of experimental conditions (e.g. solution $\mathrm{pH}$, temperature, water/cation ratio). It is, however, noted that even the smallest product of hydrolysis of a cation is sufficiently larger than the corresponding bare cation, and due to this enhanced size, can offer geometrical hindrance to small silicate polymers in approaching each other; this is expected to retard their already slow rate of condensation (shown by the very slow increase in viscosity of TEOS-derived sols). Another factor involved in this process is the competition between silicon and the dopant cation for the available water for hydrolysis; this is also known to retard the hydrolysis of TEOS (Boilot et al 1988; Patra 1992; Fukui et al 1992). 


\section{Conclusion}

Based on the previous and present information, it can probably be commented that broadly speaking (i) a hydrated cation assists gelation of a silica sol by shedding the hydration shell and cross-linking silicate polymers; and (ii) a hydrolyzed cation hinders gelation by growing in molecular size and offering size-related hindrance in the cross-linking process. This has direct bearing on predicting and manipulating the workability of a sol (i.e. time available for casting, coating etc before gelation) and thus, is of significant practical utility.

\section{Acknowledgement}

Thanks are due to the colleagues of Sol-Gel Laboratory for many discussions.

\section{References}

Aizawa M, Nosaka Y and Fujii N 1994 J. Non-Cryst. Solids 16849

Baes C F and Messmer R E 1976 The hydrolysis of cations (New York: Wiley Interscience)

Bansal N P 1990 J. Am. Ceram. Soc. 732647

Boilot J P, Pouxviel J C, Dauger A. and Wright A 1988 Mater. Res. Soc. Symp. Proc. 121121

Bottero J Y, Tchouber D, Cases J M and Flessinger F 1982 J. Phys. Chem. 863667

Clearfield A and Vaughan P A 1956 Acta Cryst. 9555

Dienert F and Wandenbulcke F 1924 Compt. Rend. 178564

Fukui T, Sakurai C and Okuyama M 1992 J. Non-Cryst. Solids 139205

Ganguli D 1988 J. Non-Cryst. Solids 101117

Greenwood N N and Eamshaw A 1984 Chemistry of the elements (Oxford: Pergamon)

Hurd C B, Rhoades J W, Gormley W G and Santora A C 1958 J. Phys. Chem. 62882

Irwin A D, Holmgren J S, Zerda T W and Jonas J 1987 J. Non-Cryst. Solids 89191

Klein L C 1987 in Design of new materials (ed) D L Cocke and A Clearfield (New York: Plenum Press) pp 39-65

Kloprogge J T, Sayken D, Jansen J B H and Geus J W 1993 J. Non-Cryst. Solids 152.207

Lopez T, Romero A and Gomez R 1991 J. Non-Cryst. Solids 127105

McCormick A V, Bell A T and Radke C J 1987 Zeolites 7193

McCormick A V, Bell A T and Radke C J 1989 J. Phys. Chem. 931733

Moeller T 1973 in Comprehensive inorganic chemistry (ed) J C Bailer, H J Emeleus, R Nyholm and A F Trotman-Dickenson (Oxford: Pergamon) vol 4 pp 1-101

Moreshead W V. Nogues J-L R and Krabill R H 1990 J. Non-Cryst. Solids 121267

Murakata T, Sato S, Ohgawara T, Watanabe W and Suzuki W 1992 J. Mater. Sci. 271567

Patra A 1992 Preparation and characterization of pure and doped silica by sol-gel processing, Ph.D. thesis, Jadavpur University, Jadavpur

Patra A and Ganguli D 1992a J. Non-Cryst. Solids 139165

Patra A and Ganguli D 1992b Trans. Indian Ceram. Soc. 51105

Ramsay J D F 1994 in Controlled particle, droplet and bubble formation (ed) D J Wedlock (Oxford: Butterworth-Heinemann) pp 1-38

Sanchez J and McCormick A 1991 Chem. Mater. 3320

Thomas I M, Payne S A and Wilke G D 1992 J. Non-Cryst. Solids 151183

Wijnen P W J G, Beelen T P M, Rummens K P J and van Santen R A 1993 J. Non-Cryst. Solids 152 127

Woignier T, Phalippou J and Zarzycki J 1984 J. Non-Cryst. Solids 63117 